\title{
Speciation and ecological risk of heavy metals and metalloid in the sediments of Zhalong Wetland in China
}

\author{
H. Ye $\cdot$ S. Zang $\cdot$ H. Xiao $\cdot$ L. Zhang
}

Received: 3 September 2013/Accepted: 9 October 2013/Published online: 30 October 2013

(C) Islamic Azad University (IAU) 2013

\begin{abstract}
A total of 271 sediments samples from the Zhalong Wetland were analyzed for concentration and distribution of $\mathrm{Hg}, \mathrm{Cd}, \mathrm{As}, \mathrm{Cu}, \mathrm{Pb}, \mathrm{Zn}, \mathrm{Cr}$, and $\mathrm{Zn}$; their speciation according to the modified European Community Bureau of Reference sequential extraction procedures and their ecological risk based on Lars Hakanson's potential ecological risk assessment and risk assessment code were made. The results can be summarized as the followings: (1) Concentrations of all metals measured were above soil background values of Songnen Plain, and their spatial distributions were distinctly different. The concentrations of metals (except $\mathrm{Pb}$ ) were high in the east, followed by the north, and were relatively low in the core zone and south. The concentration of $\mathrm{Pb}$ was high in the north, south, and west, compared with low concentration in the core zone and east. (2) The dominant proportion of $\mathrm{Pb}, \mathrm{Zn}$, and $\mathrm{Cr}$ was in the residual fraction, suggesting that they were environmental stable. The concentrations of $\mathrm{Cu}$ and $\mathrm{As}$ in the reducible fraction, the concentration of $\mathrm{Cd}$ in the acidsoluble fraction, and the concentration of $\mathrm{Hg}$ in the oxidizable fraction were relatively high, indicating they had greater environmental effects. (3) The evaluation of the ecological risk showed that $\mathrm{Cd}, \mathrm{Hg}$, and As had relatively high ecological risk index, especially the ecological risk of Cd should be paid attention to. In general, the ecological risk of the heavy metals and metalloid by zone was experimental zone $>$ buffering zone $>$ ecological tourism zone $>$ core zone.
\end{abstract}

H. Ye $\cdot$ S. Zang $(\bowtie) \cdot$ H. Xiao $\cdot$ L. Zhang

Key Laboratory of Remote Sensing Monitoring of Geographic Environment, College of Heilongjiang Province, Harbin Normal University, Harbin 150025, People's Republic of China e-mail: zsy6311@163.com
Keywords Heavy metals - Speciation - Ecological risk · Spatial distribution $\cdot$ Zhalong Wetland

\section{Introduction}

Among all the major impacts threatening ecosystems, heavy metals and metalloid play a very important role (Fu et al. 2009; Zhang et al. 2012). Because they are nondegradability and bio-concentration and bio-magnify, heavy metals and metalloid pose an ecological risk to organisms and ecosystems (Lai et al. 2005; Townsend et al. 2013). Sediments are a significant reservoir and source of metals in the aquatic environment and mediate transport and storage of hazardous metals (Guevara et al. 2005; Moriilo et al. 2004). The concentration of heavy metals and metalloid in sediments from polluted aquatic environments may be hundreds or even tens of thousands of times greater than sediments from non-polluted aquatic environments (Wang et al. 2002). Consequently, understanding the spatial distribution of heavy metals in sediments can provide the evidence of the anthropogenic impacts and is critical for environmental management and decision-making.

The toxicity and the mobility of heavy metals and metalloid in sediments depend not only on the total concentration, but also on their specific chemical form. The speciation of heavy metals provides critically important information for evaluating toxicity and ecological risk to animals and human (Fan et al. 2008; Kwon and Lee 2001). Different chemical species of heavy metals have different activity, toxicity, and mobilization (Cai et al. 2011; Lu et al. 2010; Zheng et al. 2013). The changing environment can also result in the transformation of heavy metals between particulate forms and 
dissolved form (Teasdale et al. 2003; Yu and Hu 2008). Consequently, study of the speciation of heavy metals has become an important topic in aquatic research helping to identify anthropogenic sources of pollution as well as evaluation of potential ecological risk posed by heavy metals.

The Zhalong Wetland is an important migrating and breeding site for red-crowned cranes, and Ramsar Convention listed the Zhalong Wetland as an important international wetland in 1992, essential for the protection and breeding of rare waterfowl. However, irrigation projects built around the wetland increased cultivation of arable land, and overbrowsing in the wetland, along with industrial and agricultural-contaminated water being discharged into the wetland, has threatened the natural wetland. As a result, the area of the wetland is decreasing, vegetation is degenerating, and water contamination is increasing. The environmental issues in the Zhalong Wetland require additional study.

Several studies have evaluated the risk of heavy metals in sediment (Su et al. 2011; Yi et al. 2011; Sekabira et al. 2010); however, they have mainly focus on evaluations based on total concentration of heavy metals (Monken 1997; Byzitter et al. 2012). Few studies have evaluated risk of heavy metals in sediments based on speciation ( $\mathrm{Lu}$ and Cheng 2011). The objectives of the current study were to (1) determine the concentration of heavy metals and metalloid in sediments of the Zhalong Wetland, (2) evaluate the distribution of heavy metals and metalloid in the wetland, (3) analyze speciation of heavy metals and metalloid in sediments of the Wetland, and (4) assess ecological risk of heavy metals and metalloid in the sediments.

\section{Materials and methods}

Study area

The Zhalong Wetland is located in the Western Heilongjiang Province, China. The wetland forms at the terminal end of the Wuyuer River and lies between $46^{\circ} 52^{\prime} \sim 47^{\circ} 32^{\prime} \mathrm{N}$ latitude and $123^{\circ} 47^{\prime} \sim 124^{\circ} 37^{\prime} \mathrm{E}$ longitude. The wetland is a $2,100 \mathrm{~km}^{2}$ and includes four zones: experimental zone, buffering zone, ecological tourism zone, and core zone. There are 10 townships and 40 villages in the wetland with a total population of approximately 50,000 .

Sample collection and processing

During July and August 2010, 271 surface sediment samples were randomly collected within the Zhalong Wetland (Fig. 1). The upper 0-20 cm of the sediment was collected with a stainless steel sediment sampler. The samples were placed into clean polyethylene bags and transported to the laboratory. All samples were air-dried at room temperature and sieved through a $0.149 \mathrm{~mm}$ sieve.

Sample testing methods

For total heavy metals and metalloid analysis, $0.5 \mathrm{~g}$ of each dry sediment sample was digested in a microwave oven (Mars-5, CEM Company, USA) with a mixture of acid $\left(9 \mathrm{ml}\right.$ of $14.0 \mathrm{M} \mathrm{HNO}_{3}, 3 \mathrm{ml}$ of $11.7 \mathrm{M} \mathrm{HCl}$, $2 \mathrm{ml}$ of $23.0 \mathrm{M} \mathrm{HF}$, and $2.5 \mathrm{ml}$ of $\left.8.8 \mathrm{M} \mathrm{H}_{2} \mathrm{O}_{2}\right)(\mathrm{Hu}$ and Qian 2010). For the analysis of heavy metal and
Fig. 1 Location of Zhalong Wetland and sampling site

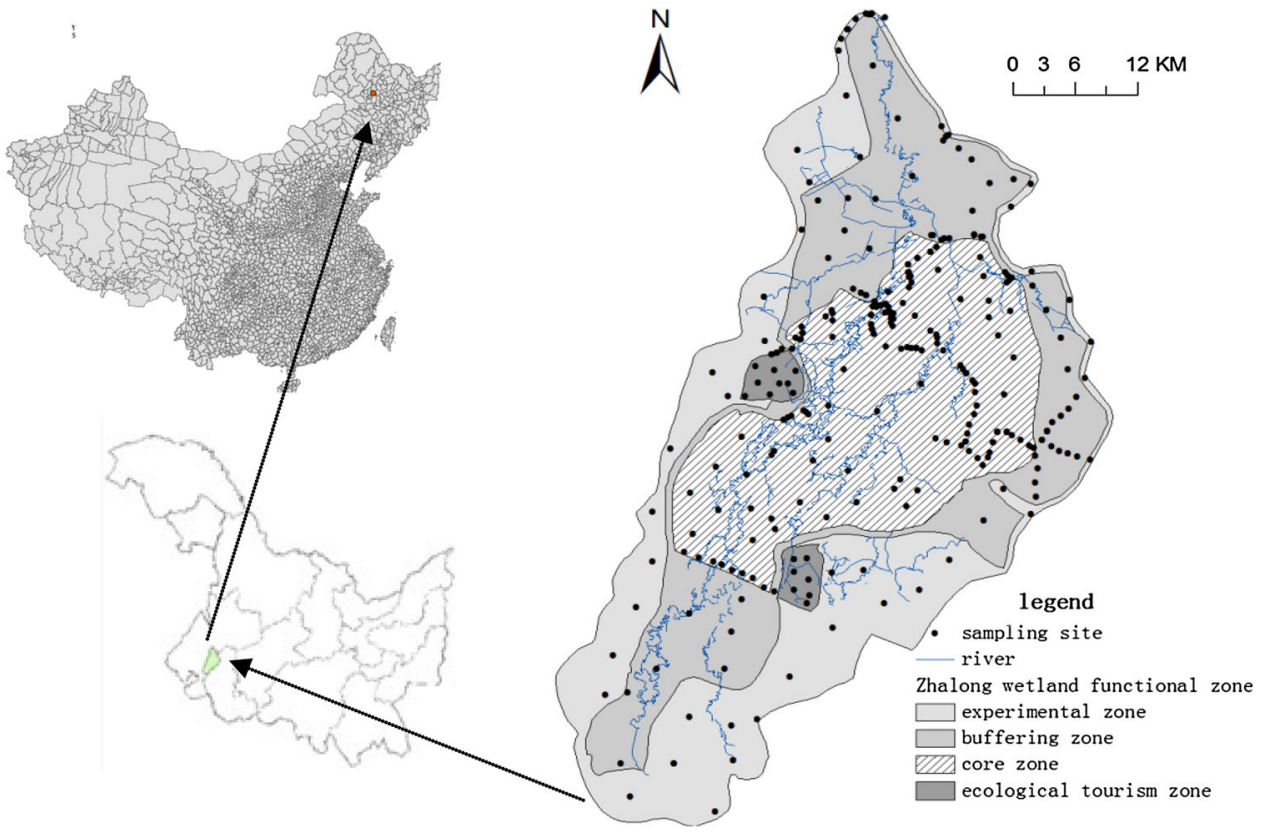


metalloid species, the acid-soluble, oxidizable, reducible, and residual fractions were sequentially extracted following European Community Bureau of Reference (BCR) methods (Guevara-Riba et al. 2004; Arain et al. 2008; Malferrari et al. 2009). All samples were analyzed using an inductively coupled plasma mass spectrometer (ICP-MS) (Agilent Technologies Co. Ltd., USA). Quality control was assured by the analysis of duplicate samples, method blanks, and standard reference materials. A duplicate and method blank were analyzed with each batch of 10 samples, and precision was generally $<10 \%$ relative standard deviation. The standard reference material (ESS-1, obtained from Chinese Environmental Monitoring Center) was used for total element analysis. Cooper, $\mathrm{Cr}$, and $\mathrm{Zn}$ values had an accuracy within $5 \%$ based on the mean values, while the other elements $(\mathrm{Cd}, \mathrm{Hg}$, $\mathrm{As}$, and $\mathrm{Pb})$ had an accuracy between 5 and $10 \%$. The ratios of cumulative concentrations of the four fractions to the independent total concentrations of $\mathrm{Hg}, \mathrm{Cd}, \mathrm{As}, \mathrm{Cu}, \mathrm{Pb}, \mathrm{Cr}$, and $\mathrm{Zn}$ were $91,96,92,105,103,98$, and $101 \%$, respectively. Lake sediment for extractable trace elements (GBW07436, obtained from the Chinese National Research Center for Geoanalysis and Chinese National Institute of Metrology) was used to verify the accuracy of the sequential extraction method. The recovery rate of each fraction of the heavy metals and metalloid was between 86.6 and $110.1 \%$.

\section{Statistics analysis}

Statistical analyses were performed using SPSS for Windows 11.0 software. The concentrations of the metals were compared among regions (east, south, west, north, and core) of the wetland using one-way ANOVA $(P<0.05)$. Shapiro-Wilk test was used to evaluate normality of the distribution of heavy metals and metalloid. Spatial distribution mapping of heavy metals and metalloid parameters was created with ArcGIS 8.3 and ArcView 3.2 software.
Ecological risk assessment

To assess the impacts of heavy metals and metalloid in Zhalong Wetland, two different benchmark methods were used. The first method was Hakanson's potential ecological risk index (HPERI, Hakanson 1980). The methodology is based on the assumption that the sensitivity of the aquatic system depends on its productivity. The HPERI was used to assess the degree of heavy metal pollution in sediments, based on the toxicity of heavy metals and the response of the environment. The index was calculated using the following equations:

$\mathrm{RI}=\sum_{i=1}^{n} E_{r}^{i}$

$E_{r}^{i}=T_{r}^{i} C_{f}^{i}$

$C_{f}^{i}=C^{i} / C_{n}^{i}$

where $C_{f}^{i}$ : the pollution coefficient of single metal; $C^{i}$ : the measured concentration of sample; $C_{n}^{i}$ : the background concentration of sediments; $T_{r}^{i}$ : the biological toxicity factor of different metals (the factors of $\mathrm{Hg}, \mathrm{Cd}, \mathrm{As}, \mathrm{Cu}$, $\mathrm{Pb}, \mathrm{Cr}$, and $\mathrm{Zn}$ were 40, 30, 10, 5, 5, 2, and 1, respectively); $E_{r}^{i}$ : the potential ecological risk factor of single metal; RI: the potential ecological risk index of many metals (Table 1).

Because there are no environmental quality criteria established for river and lake sediments in China, it is common to use regional soil background concentration as evaluation criteria. In the current study, the regional background values of metals in the soil on Songnen Plain of Heilongjiang Province were used as a reference (Liu and Zhao 1987).

The second method was the Risk Assessment Code (RAC) classification based on the percentage of metals in the carbonate and exchangeable fractions (Singh et al. 2005). The classification is based on the strength of the bond between metals and the different geochemical fractions in sediments and the ability of metals to be released

Table 1 The grade of ecological risk coefficient, risk index, and classification of risk intensity

\begin{tabular}{llll}
\hline$E_{r}^{i}$ & Grade for ecological risk & RI & Grade for ecological risk \\
\hline$E_{r}^{i}<40$ & Low & RI $<135$ & Low \\
$40 \leq E_{r}^{i}<80$ & Moderate & $135 \leq \mathrm{RI}<265$ & Moderate \\
$80 \leq E_{r}^{i}<160$ & Considerable & $265 \leq \mathrm{RI}<525$ & High \\
$160 \leq E_{r}^{i}<320$ & High & RI $\geq 525$ & Very high \\
$E_{r}^{i} \geq 320$ & Very high & - & - \\
\hline
\end{tabular}

Assessment of heavy metal and metalloid pollution in surface sediments of the Zhalong Wetland by Hakanson's potential ecological risk method ( $E_{r}^{i}$ and RI) (Cai et al. 2011) 
Table 2 Concentrations and regional background value of heavy metals and metalloid in sediments $(n=271)$ of the Zhalong Wetland $\left(\mathrm{mg} \mathrm{kg}^{-1}\right)$

\begin{tabular}{lccccccc}
\hline & $\mathrm{Hg}$ & $\mathrm{Cd}$ & $\mathrm{As}$ & $\mathrm{Cu}$ & $\mathrm{Pb}$ & $\mathrm{Cr}$ & $\mathrm{Zn}$ \\
\hline Minimum & 0.01 & 0.022 & 2.99 & 9.99 & 16.43 & 24.1 & 25.4 \\
Maximum & 0.208 & 0.713 & 22.04 & 48.6 & 29.07 & 68.46 & 76.32 \\
Mean & 0.065 & 0.155 & 10.26 & 18.17 & 21.38 & 46.47 & 52.09 \\
C.V. $(\%)^{\mathrm{a}}$ & 47.2 & 58.6 & 36.1 & 16.5 & 19.7 & 20.7 & 13.5 \\
Background value $^{\mathrm{b}}$ & 0.031 & 0.073 & 9.14 & 17.78 & 20.23 & 42.46 \\
\hline
\end{tabular}

${ }^{a} C . V$ coefficient of variation

b The soil background value on Songnen Plain of Heilongjiang Province

Table 3 Maximum $\mathrm{Hg}, \mathrm{Cd}, \mathrm{As}, \mathrm{Cu}, \mathrm{Pb}, \mathrm{Cr}$, and $\mathrm{Zn}$ in sediments of Zhalong Wetland and other water bodies from the literature

\begin{tabular}{lllllllll}
\hline Site & \multicolumn{3}{l}{ Maximum concentration $\left(\mathrm{mg} \mathrm{kg}^{-1}\right)$} & & \multicolumn{3}{c}{ Reference } \\
\cline { 2 - 7 } & $\mathrm{Hg}$ & $\mathrm{Cd}$ & $\mathrm{As}$ & $\mathrm{Cu}$ & $\mathrm{Pb}$ & $\mathrm{Cr}$ & $\mathrm{Zn}$ & \\
\hline Zhalong Wetland, China & 0.208 & 0.713 & 22.04 & 48.60 & 29.07 & 68.46 & 76.32 & This study \\
Baiyangdian Wetland, China & 0.06 & 0.90 & 24.8 & 35 & 30 & 84 & 112 & Su et al. (2011) \\
Taihu Lake, China & - & - & - & 42.13 & 47.24 & - & 138.7 & Chen et al. (2011) \\
Yellow River, China & - & - & 50.0 & 110.0 & 80.0 & 130.0 & 210.0 & Liu et al. (2009) \\
Hengshuihu Wetland, China & 0.21 & 0.023 & 51.30 & 41.72 & 38.9 & 85.98 & 270.3 & Zhang et al. (2009) \\
Vembanad Wetland, India & - & 0.73 & - & 49.43 & 54.42 & - & 211.3 & Harikumar et al. (2009) \\
Thermaikos Gulf, N. Greece & - & - & - & 165 & 218 & 172 & 358 & Christophoridis et al. (2009) \\
Gulf of Lions, Mediterranean Sea & - & 0.82 & - & 45.8 & 69.7 & 117.3 & 144.9 & Roussiez et al. (2006) \\
\hline
\end{tabular}

The heavy metal of this study compared to the findings of other rivers, wetlands, and lakes

and enter into the food chain. The carbonate and exchangeable fractions are considered to be weakly bonded metals, which may equilibrate with the aqueous phase and become more rapidly bioavailability (Hseu 2006; Yan et al. 2010). According to RAC, if the carbonate and exchangeable fractions are lower than $1 \%$, there is no risk for the aquatic system, low risk for a range of 1-10\%, medium risk for a range of $11-30 \%$, and high risk for a range of $31-50 \%$, and higher than $50 \%$ is considered very high risk (Yan et al. 2010).

\section{Results and discussion}

Concentrations of heavy metals and metalloid in sediments

The concentrations of heavy metals and metalloids in sediments of the Zhalong Wetland were very similar to that of global shale heavy metals, with concentrations following the order $\mathrm{Zn}>\mathrm{Cr}>\mathrm{Cu}>\mathrm{Pb}>\mathrm{As}>\mathrm{Cd}>$ Hg (Turekian and Wedepohl 1961). The mean concentrations of all metals measured in the Zhalong Wetland were above soil background values of the Songnen Plain (Table 2). Concentrations of $\mathrm{Hg}$ and $\mathrm{Cd}$ were 2.1 times above background concentrations. Compared to the findings of other rivers, wetlands, and lakes (Table 3), concentrations of $\mathrm{As}, \mathrm{Cu}, \mathrm{Pb}, \mathrm{Cr}$, and $\mathrm{Zn}$ in sediments of the Zhalong Wetland were relatively lower. The concentration of $\mathrm{Hg}$ was similar to Hengshuihu Wetland in China, but 34.6 times that of Baiyangdian Wetland in China. The concentration of $\mathrm{Cd}$ was similar to that of Vembanad Wetland in India, Gulf of Lions in Mediterranean Sea, and Baiyangdian Wetland in China, but 31 times that of Hengshuihu Wetland in China. Hence, $\mathrm{Hg}$ and $\mathrm{Cd}$ should gain enough attention in sediments of the Zhalong Wetland.

The coefficients of variation of $\mathrm{Hg}, \mathrm{Cd}, \mathrm{As}, \mathrm{Cu}, \mathrm{Pb}, \mathrm{Cr}$, and $\mathrm{Zn}$ were 47.2, 58.6, 36.1, 16.5, 19.7, 20.7, and $13.5 \%$, respectively (Table 2), all above $10 \%$. Especially for $\mathrm{Hg}$ and $\mathrm{Cd}$, the coefficients of variation $(\mathrm{CV} \%)$ were over $40 \%$, indicating contamination that was probably caused by anthropogenic sources (Chouba and Mzoughi 2013). High concentrations (i.e., above background levels) coupled with a high $\mathrm{CV} \%$ suggest anthropogenic inputs of metal elements (Manta et al. 2002). 

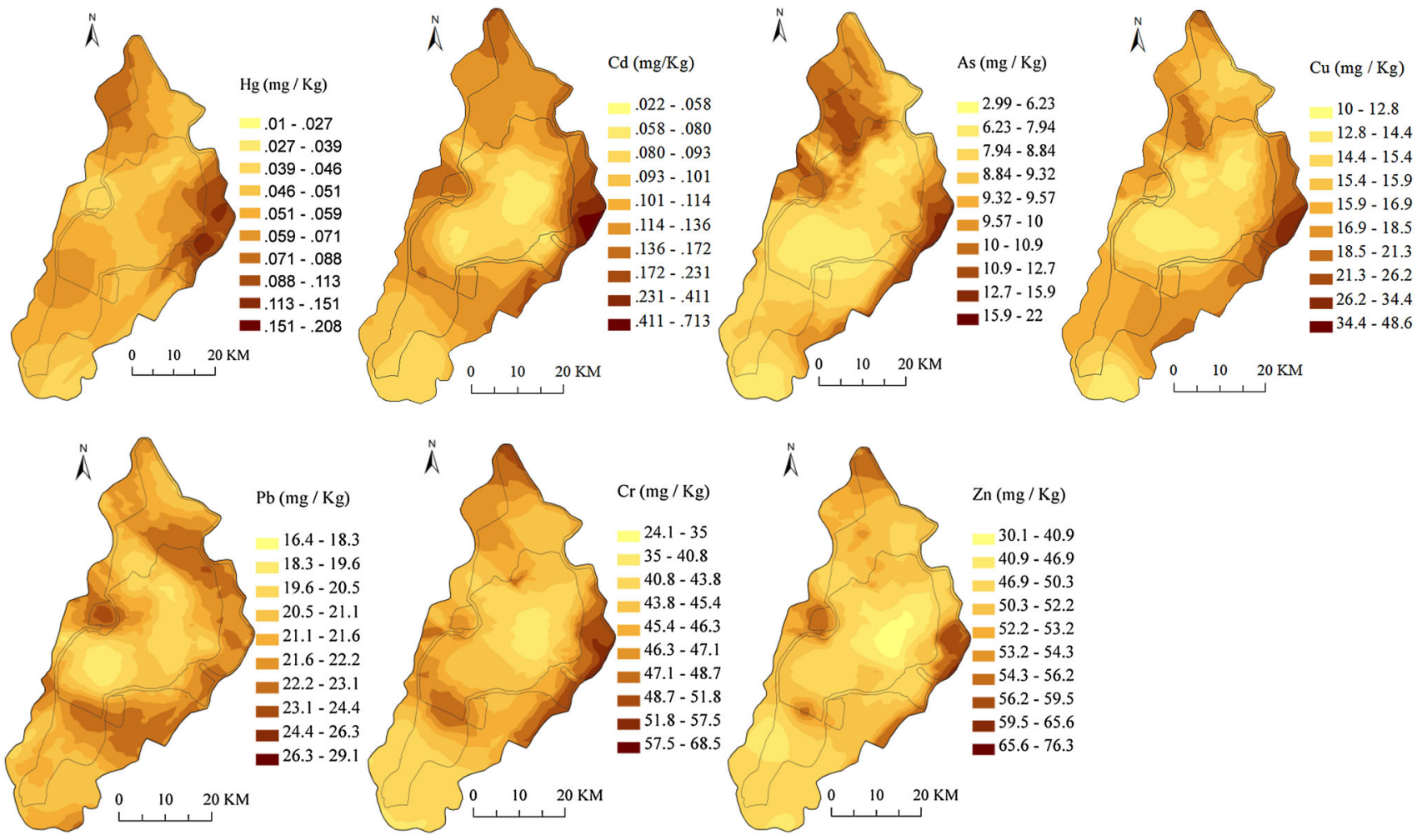

Fig. 2 Spatial distribution of heavy metals and metalloid in sediments of the Zhalong Wetland $(n=271)$

Spatial distribution of heavy metals and metalloid in sediments

The spatial distributions of heavy metals and metalloid in sediments of the Zhalong Wetland were shown in Fig. 2. Concentrations of the metals (except for $\mathrm{Pb}$ ) were high in the east, followed by the north $(P<0.05)$, and generally low in the south region and core zone of the study area. Especially in the east region, the concentrations of $\mathrm{Hg}, \mathrm{Cd}, \mathrm{As}, \mathrm{Cu}, \mathrm{Cr}$, and $\mathrm{Zn}$ were $0.208,0.713,22.04,48.60,68.46$, and $76.32 \mathrm{mg} \mathrm{kg}^{-1}$, respectively, reaching the maximum value in the whole region. The concentrations of $\mathrm{Cd}, \mathrm{Hg}$, As, and $\mathrm{Cu}$ were $32.4,20.8,7.4$, and 4.8 times the minimum value of the whole area, respectively. The concentration of $\mathrm{Pb}$ was high in the north, south, and west regions, compared with low concentration in the east region and core zone $(P<0.05)$.

The spatial distribution of the metals, however, indicated that it had been apparently affected by the surrounding agriculture and industry (Mohiuddin et al. 2010; Karbassi et al. 2006). In the north region of the study area, the concentrations of metals (except for $\mathrm{Pb}$ ) were high. The main reason was that the agricultural-contaminated water from the upper of Wuyuer River and counties around was discharged into the wetland. Due to the low speed of flowing, great amount of heavy metals and metalloid were subsided in the sediments. The concentrations of heavy metals and metalloid in the east were also high. It was because the industrial-contaminated water of Lindian County was discharged into the wetland directly or indirectly, such as sugar refinery, machinery factory, and chemical plant. The spatial distribution of $\mathrm{Pb}$ was mainly impacted by exhaust from vehicles and tourism. Because new 301 national road in the north and Binzhou railway in the south pass through the wetland, the concentration of $\mathrm{Pb}$ was high in the north and south regions, and the high in the east was affected by the ecological tourism.

Speciation of heavy metals and metalloid in sediments

The modified BCR sequential extraction scheme indicated that $\mathrm{Pb}, \mathrm{Zn}$, and $\mathrm{Cr}$ existed mainly in the residual fraction; their mean percentages were 82,92 , and $88 \%$, respectively (Table 4). The mean percentages of the acid-soluble fraction of $\mathrm{Pb}, \mathrm{Zn}$, and $\mathrm{Cr}$ were lower than $5 \%$. The dominant proportions of $\mathrm{Cd}$ were primary in the acid-soluble fraction (37\%), the residual fraction (34\%), and the oxidizable fraction $(21 \%)$. Different from $\mathrm{Cd}, \mathrm{Hg}$ existed mainly in the residual (62\%) and oxidizable (20\%) fractions, while the acid-soluble $(9 \%)$ and oxidizable $(9 \%)$ fractions were relatively low. In contrast, $\mathrm{As}$ and $\mathrm{Cu}$ existed mainly as the residual and reducible fractions. 
Table 4 Speciation compositions and average content of heavy metals and metalloid in sediments $(n=271)$ of the Zhalong Wetland

\begin{tabular}{|c|c|c|c|c|c|c|}
\hline \multicolumn{2}{|c|}{ Heavy metal } & \multicolumn{4}{|c|}{ Speciation composition (wt\%) } & \multirow[t]{2}{*}{ Mean content ${ }^{\mathrm{b}}\left(\mathrm{mg} \mathrm{kg}^{-1}\right)$} \\
\hline & & $\mathrm{F}_{1}^{\mathrm{a}}$ & $\mathrm{F}_{2}^{\mathrm{a}}$ & $\mathrm{F}_{3}^{\mathrm{a}}$ & $\mathrm{F}_{4}^{\mathrm{a}}$ & \\
\hline \multirow[t]{2}{*}{$\mathrm{Hg}$} & Range & $0-28$ & $2-16$ & $6-55$ & $21-86$ & 0.059 \\
\hline & Mean & 9 & 9 & 20 & 62 & \\
\hline \multirow[t]{2}{*}{$\mathrm{Cd}$} & Range & $0-66$ & $2-14$ & $4-31$ & $25-83$ & 0.149 \\
\hline & Mean & 37 & 8 & 21 & 34 & \\
\hline \multirow[t]{2}{*}{ As } & Range & $0-16$ & $6-51$ & $3-16$ & $32-82$ & 9.45 \\
\hline & Mean & 7 & 21 & 6 & 66 & \\
\hline \multirow[t]{2}{*}{$\mathrm{Cu}$} & Range & $1-8$ & $0-55$ & $0-19$ & $43-85$ & 19.2 \\
\hline & Mean & 4 & 18 & 7 & 71 & \\
\hline \multirow[t]{2}{*}{$\mathrm{Pb}$} & Range & $0-9$ & $2-19$ & $0-21$ & $66-94$ & 22.2 \\
\hline & Mean & 4 & 6 & 8 & 82 & \\
\hline \multirow[t]{2}{*}{$\mathrm{Cr}$} & Range & $0-9$ & $1-8$ & $0-18$ & $72-97$ & 45.6 \\
\hline & Mean & 3 & 4 & 5 & 88 & \\
\hline \multirow[t]{2}{*}{$\mathrm{Zn}$} & Range & $0-6$ & $0-11$ & $1-12$ & $75-98$ & 52.5 \\
\hline & Mean & 1 & 3 & 4 & 92 & \\
\hline
\end{tabular}

a $\mathrm{F}_{1}$ : the acid-soluble fraction (exchangeable and bound to carbonate); $\mathrm{F}_{2}$ : the reducible fraction (the bound to Fe/Me oxide); $\mathrm{F}_{3}$ : the oxidizable fraction (the bound to organic matter and sulfide); $\mathrm{F}_{4}$ : the residual fraction

b Mean content $=$ mean concentration of $\left(\mathrm{F}_{1}+\mathrm{F}_{2}+\mathrm{F}_{3}+\mathrm{F}_{4}\right)$

Table 5 General and individual indices of potential ecological risk in sediments $(n=271)$ of the Zhalong Wetland

\begin{tabular}{|c|c|c|c|c|c|c|c|c|}
\hline & \multicolumn{7}{|l|}{$E_{r}^{i}$} & \multirow[t]{2}{*}{ RI } \\
\hline & $\mathrm{Hg}$ & $\mathrm{Cd}$ & As & $\mathrm{Cu}$ & $\mathrm{Pb}$ & $\mathrm{Cr}$ & $\overline{\mathrm{Zn}}$ & \\
\hline Minimum & 12.9 & 9.0 & 3.3 & 2.8 & 4.1 & 1.1 & 0.6 & 76.9 \\
\hline Maximum & 268.4 & 293.0 & 24.1 & 13.7 & 7.2 & 3.2 & 1.5 & 473.5 \\
\hline Mean & 83.3 & 63.8 & 11.2 & 5.1 & 5.3 & 2.2 & 1.0 & 171.9 \\
\hline
\end{tabular}

In general, the mean percentage of the acid-soluble fraction of heavy metals and metalloid in sediments of the Zhalong Wetland followed the order: $\mathrm{Cd}>\mathrm{Hg}>\mathrm{As}>$ $\mathrm{Cu}=\mathrm{Pb}>\mathrm{Cr}>\mathrm{Zn}$. The reducible, oxidizable, and residual fractions followed the order: $\mathrm{As}>\mathrm{Cu}>\mathrm{Hg}>\mathrm{Cd}$ $>\mathrm{Pb}>\mathrm{Cr}>\mathrm{Zn} ; \mathrm{Cd}>\mathrm{Hg}>\mathrm{Pb}>\mathrm{Cu}>\mathrm{As}>\mathrm{Cr}>\mathrm{Zn}$; and $\mathrm{Zn}>\mathrm{Cr}>\mathrm{Pb}>\mathrm{Cu}>\mathrm{As}>\mathrm{Hg}>\mathrm{Cd}$, respectively.

The speciation distribution of the metals in sediments of the Zhalong Wetland indicated that different metals had different speciation in the same site, and the same metal had different speciation at different sites as well. The reason was that the speciation of metals was influenced not only by its geochemistry characteristics but also by the human activities and the physical and chemical features of the sediments (Feng et al. 2009; Wang et al. 2012).

As found by other study (Wang et al. 2011), the percentage of the acid-soluble fraction of $\mathrm{Cd}$ in the Zhalong Wetland was high. The reason could be related to its adsorption behavior in sediments, its strong chemistry activity, and human activities as well. This fraction easily transferred, and its biological validity and toxicity are the strongest among the four fractions.

In the reducible fraction, the percentages of $\mathrm{As}$ and $\mathrm{Cu}$ were high among all the metals, ranging 6-51\% (mean $21 \%$ ) and $0-47 \%$ (mean $18 \%$ ), respectively. The reducible fraction of heavy metals was quite sensitive to oxidation-reduction potential (ORP) (Dang and Jeffrey 2006). The low ORP in sediments of the Zhalong Wetland indicated that it was in a weak reduction environment. As and $\mathrm{Cu}$ in the reducible fraction would be easily released under deoxidization and pose as second pollution on water, which should be gained enough attention.

In the oxidizable fraction, the percentages of $\mathrm{Hg}$ and $\mathrm{Cd}$ were high. They mainly distribute in southwest of the core zone, where the concentration of organic matter in sediments was high. It indicated that the organic matter and sulfide in the sediments had a strong adsorbing capacity of $\mathrm{Hg}$ and $\mathrm{Cd}$. On the other hand, $\mathrm{Pb}, \mathrm{Cr}$, and $\mathrm{Zn}$ mainly existed as the residual fraction, indicating that a big part of those metals was bounded in the crystal lattice 


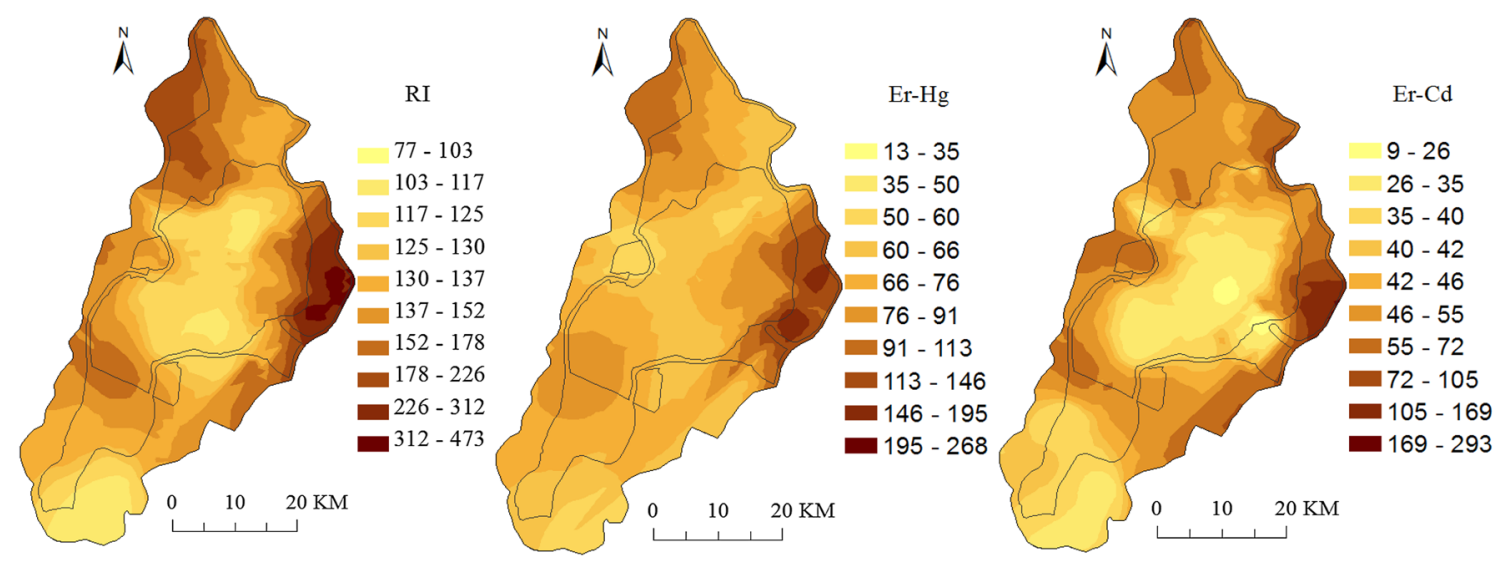

Fig. 3 Spatial distribution of RI, Er-Hg, and Er-Cd in sediments of the Zhonglong Wetland $(n=271)$

of mineral, and their potential bio-toxicity were relatively small.

Assessment of heavy metal and metalloid pollution in sediments by Hakanson's potential ecological risk

The mean of ecological factors $\left(E_{r}^{i}\right)$ for $\mathrm{As}, \mathrm{Pb}, \mathrm{Cu}, \mathrm{Zn}$, and $\mathrm{Cr}$, was $11.2,5.3,5.1,1.0$, and 2.2 , respectively (Table 5), indicating low ecological risk (i.e., <40) according to the evaluated standards for analyzing the potential ecological risk. The mean $E_{r}^{i}$ for $\mathrm{Hg}$ was 83.3 (range 12.9-268.4), indicating considerable potential for ecological risk, while the mean for $\mathrm{Cd}$ was 63.8 (range 9.0-293.0), indicating moderate ecological risk. The sequence of the potential ecological risk posed by the metals was $\mathrm{Hg}>\mathrm{Cd}>\mathrm{As}>\mathrm{Pb}>\mathrm{Cu}>\mathrm{Cr}>\mathrm{Zn}$. The average potential ecological risk indices (RI) of the Zhalong Wetland was 171.9 (range 76.9-473.5), suggesting moderate ecological risk.

Because $\mathrm{Hg}$ and $\mathrm{Cd}$ indicated risk, both were chosen as the basis for a single potential ecological risk index of heavy metals. The spatial distribution of $\mathrm{Hg}$ and $\mathrm{Cd}$ as a single potential ecological risk index and heavy metal general potential ecological risk indices (RI) in surface sediments of the Zhalong Wetland had distinct spatial distribution (Fig. 3).

The potential ecological risk index (RI) had similar spatial distribution with that of $E_{r}^{i}$ for $\mathrm{Cd}(\mathrm{Er}-\mathrm{Cd})$ and $E_{r}^{i}$ for $\mathrm{Hg}(\mathrm{Er}-\mathrm{Hg})$. The potential risk $\mathrm{Er}-\mathrm{Hg}, \mathrm{Er}-\mathrm{Cd}$, and the RI mainly occurred in the experimental and buffering zones of the Zhalong Wetland, especially the eastern part of these two zones indicated high ecological risk area. In addition, a small part of the core zone had potential ecological risk as well.
Assessment of heavy metal and metalloid pollution in sediments by using RAC

The RAC classification results indicated that the percentages of the exchangeable and carbonate fractions of $\mathrm{Cu}, \mathrm{Pb}$, $\mathrm{Cr}$, and $\mathrm{Zn}$ were between $1-8,0-9,0-9$, and $0-6 \%$, respectively, lower than $10 \%$, indicating no or low risk. The percentages of the exchangeable and carbonate fractions of $\mathrm{Hg}, \mathrm{Cd}$, and As were 0-28, 0-66, and 0-16\%, respectively; their maximum value were all above $10 \%$, indicating medium or greater risk.

Because $\mathrm{Hg}, \mathrm{Cd}$, and As indicated risk, they were chosen as the core for RAC. The percentages of the exchangeable and carbonate fractions of $\mathrm{Hg}, \mathrm{Cd}$, and $\mathrm{As}$ had distinct spatial distribution (Fig. 4). The percentage of the exchangeable and carbonate fractions of $\mathrm{Hg}$ and As was higher than $10 \%$, but lower than $30 \%$ in the northern and eastern part of the study area, indicating medium risk, while in other part of the study area, the number was lower than $10 \%$, indicating no or low risk. The mean percentage of the exchangeable and carbonate fractions of $\mathrm{Cd}$ in the whole wetland was greater than $10 \%$ (indicating medium risk), while in the eastern part, it ranged between 19 and $66 \%$ (mean $=37 \%$ ), indicating high risk. In a small region of the eastern area, the mean percentage of exchangeable and carbonate fractions of $\mathrm{Cd}$ was greater than $50 \%$, indicating very high risk.

Both Hakanson's ecological risk method and RAC were used to evaluate the ecological risk of heavy metals in the sediments. We found the same results that the grades for ecological risk $(\mathrm{Cu}, \mathrm{Pb}, \mathrm{Zn}$, and $\mathrm{Cr})$ were in low level using these two different methods, which had no impact on benthic life. However, the potential ecological risk indices of $\mathrm{Hg}, \mathrm{Cd}$, and $\mathrm{As}$ were high, 


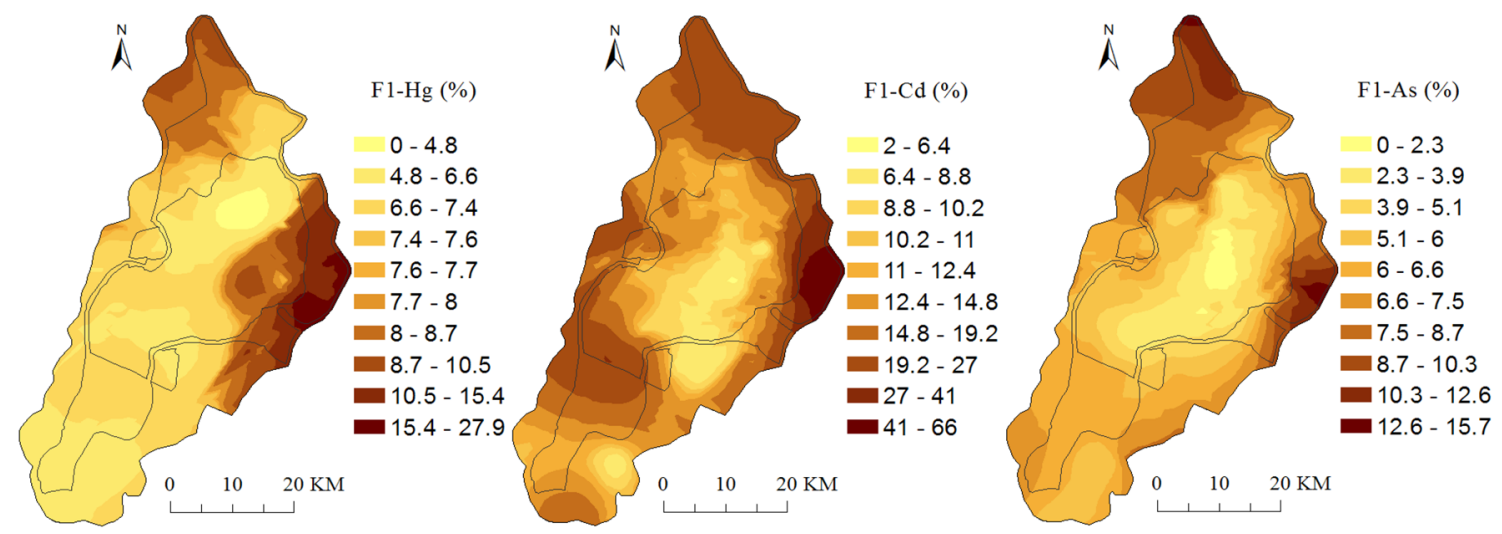

Fig. 4 Spatial distribution of the percentage of the exchangeable and carbonate fractions of $\mathrm{Hg}, \mathrm{Cd}$, and $\mathrm{As}\left(\mathrm{F}_{1}-\mathrm{Hg}, \mathrm{F}_{1}-\mathrm{Cd}, \mathrm{F}_{1}-\mathrm{As}\right)(n=271)$

especially for $\mathrm{Hg}$ and $\mathrm{Cd}$. Under Hakanson's ecological risk method, the grade for ecological risk of $\mathrm{Hg}$ was moderate in the core zone and considerable or high in the northern and eastern part of the buffering zone and experimental zone. While under RAC, the grade for ecological risk for $\mathrm{Hg}$ was moderate in the northern and eastern part of the buffering zone and experimental zone, because $\mathrm{Hg}$ was mainly abundant in the residential fraction, suggesting that they may have less potential ecological pollutions to the water environment. The potential ecological risk index of $\mathrm{Cd}$ was similar to the two methods. It was high in the eastern part of the experimental zone and buffering zone, which posed great impact on benthic life. These areas should be treated as the major heavy metal pollution prevention sites. A small portion of the ecological tourism zone and core zone had potential ecological risk as well, which should be paid enough attention by the local authorities. In general, the ecological risks of the heavy metals by the different zones were as follows: experimental zone $>$ buffering zone $>$ ecological tourism zone $>$ core zone.

\section{Conclusion}

The mean concentrations of all metals measured were above soil background values of the Songnen Plain. Especially for $\mathrm{Hg}$ and $\mathrm{Cd}$, their concentrations were 2.1 times above soil background concentrations. The concentrations of the metals (except for $\mathrm{Pb}$ ) were generally low in the south region and the core zone of the study area, and high in the north and east regions. The concentration of $\mathrm{Pb}$ was high in the north, south, and west regions, compared with low concentration in the east region and the core zone.

The modified BCR sequential extraction scheme indicated that $\mathrm{Pb}, \mathrm{Zn}$, and $\mathrm{Cr}$ existed mainly in the residual fraction, indicating that a big part of those metals were bounded in the crystal lattice of mineral and their potential bio-toxicity were relatively small. The concentration of $\mathrm{Cd}$ in the acid-soluble fraction was high, indicating that it had greater toxicity and mobility. Except for their main residual fraction, the concentrations of $\mathrm{Hg}$ in oxidizable fraction, and $\mathrm{As}$ and $\mathrm{Cu}$ in reducible fraction, were relatively high as well, indicating they had greater environmental effects than $\mathrm{Pb}, \mathrm{Zn}$, and $\mathrm{Cr}$.

The grades for ecological risk $(\mathrm{Cu}, \mathrm{Pb}, \mathrm{Zn}$, and $\mathrm{Cr}$ ) were in low level, using these two different methods, indicating they had no impact on benthic life. The evaluation of the ecological risk showed that $\mathrm{Cd}, \mathrm{Hg}$, and As had relatively high ecological risk index. Especially for $\mathrm{Cd}$, it was determined to be the main contamination indicators. Therefore, Cd may be the most important threat for the environment in the Zhalong Wetland, which should be paid enough attention by the local authorities.

Acknowledgments This research was financially supported by Scientific Research Fund of the National Natural Science Foundation of China (No.41030743), Heilongiiang Provincial Education Department (No. 2010td10), and Harbin Normal University (No. 09xkyy11). We thank Modern Experimental Center of Harbin Normal University for sample testing. Thanks to Dr. Ji-Dong Gu in the University of Hong kong and Dr. Richard S. Halbrook in Southern Illionis University for their help and suggestions to the draft manuscript.

\section{References}

Arain MB, Kazi TG, Jamali MK, Jalbani N, Afridi HI, Baig JA (2008) Speciation of heavy metals in sediment by conventional, ultrasound and microwave assisted single extraction methods: a comparison with modified sequential extraction procedure. J Hazard Mater 154:998-1006

Byzitter J, Lukowiak K, Karnik V, Dalesman S (2012) Acute combined exposure to heavy metals ( $\mathrm{Zn}, \mathrm{Cd}$ ) blocks memory formation in a freshwater snail. Ecotoxicology 21:860-868

Cai JN, Cao YZ, Tan HJ, Wang YM, Luo JQ (2011) Fractionation and ecological risk of metals in urban river sediments in Zhongshan City, Pearl River Delta. Environ Monit 13:2450-2456 
Chen CX, Jiang X, Zhan YZ, Jin XC, Zhao Z (2011) Speciation distribution and potential ecological risk assessment of heavy metals in sediments of Taihu Lake. China Environ Sci 31(11):1842-1848 (in Chinese)

Chouba L, Mzoughi N (2013) Assessment of heavy metals in sediment and in suspended particles affected by multiple anthropogenic contributions in harbours. Int $\mathrm{J}$ Environ Sci Technol 10:779-788

Christophoridis C, Dedepsidis D, Fytianos K (2009) Occurrence and distribution of selected heavy metals in the surface sediments of Thermaikos Gulf, N. Greece. Assessment using pollution indicators. J Hazard Mater 168(2-3):1082-1091

Dang TC, Jeffrey PO (2006) Metal speciation in coastal marine sediments from Singapore using a modified BCR-sequential extraction procedure. Appl Geochem 21(8):1335-1346

Fan WH, Zhang B, Zhang R (2008) Speciation characteristics and potential ecological risk of heavy metals in surface sediments of Jinzhou Bay. Mar Environ Sci 27(1):54-58 (in Chinese)

Feng XD, Dang Z, Huang WL, Yang C (2009) Chemical speciation of fine particle bound trace metals. Int $\mathrm{J}$ Environ Sci Technol 6(3):337-346

Fu C, Guo J, Pan J, Qi JS, Zhou WS (2009) Potential ecological risk assessment of heavy metal pollution in sediments of the Yangtze river within the Wanzhou section, China. Biol Trace Elem Res 129:270-277

Guevara R, Rizzo A, Sanchez R (2005) Heavy metal inputs in northern Patagonia lakes from short sediments core analysis. Mar Chem 265(3):481-493

Guevara-Riba A, Sahuquillo A, Rubio R, Rauret G (2004) Assessment of metal mobility in dredged harbour sediments from Barcelona, Spain. Sci Total Environ 321:241-255

Hakanson L (1980) An ecological risk index for aquatic pollution control: a sedimentological approach. Water Res 14(8):975-1001

Harikumar PS, Nasir UP, Rahman MPM (2009) Distribution of heavy metals in the core sediments of a tropical wetland system. Int $\mathbf{J}$ Environ Sci Tech 6(2):225-232

Hseu ZY (2006) Extractability and bioavailability of zinc over time in three tropical soils incubated with biosolids. Chemosphere 63:762-771

Hu SS, Qian XF (2010) Application of microwave resolution technology in determination of heavy metal in soil. J Anhui Normal Univ (Nat Sci) 33(4):363-366 (in Chinese)

Karbassi AR, Bayati I, Moattar F (2006) Origin and chemical partitioning of heavy metals in riverbed sediments. Int J Environ Sci Technol 3(1):35-42

Kwon YT, Lee CW (2001) Ecological risk assessment of sediment in waster water discharging area by means of metal speciation. Microchem J 70:255-264

Lai MY, Shen P, Gu J-D (2005) Heavy metals in the benthic infauna gastropoda (Sermyla riqueti and Stenothyra devalis) of Mai Po nature reserve and inner deep Bay Ramsar Site of Hong Kong. Bull Environ Contam Toxicol 74:1065-1071

Liu XJ, Zhao YL (1987) A preliminary study on the background values of 8 heavy metallic elements and relevant factors on Songnen Plain. J Northeast Agric Coll 18(2):114-118 (in Chinese)

Liu C, Xu J, Liu C, Zhang P, Dai M (2009) Heavy metals in the surface sediments in Lanzhou Reach of Yellow River, China. Bull Environ Contam Toxicol 82(1):26-30

Lu CX, Cheng JM (2011) Speciation of heavy metals in the sediments from different eutrophic lakes of China. Procedia Eng $18: 318-323$

Lu SY, Jiao W, Jin XC (2010) Speciation of heavy metals in sediments from inner lakeside belt of Lake Dianchi. China Environ Sci 30(4):487-492 (in Chinese)
Malferrari D, Brigatti MF, Laurora A, Pini S (2009) Heavy metals in sediments from canals for water supplying and drainage: mobilization and control strategies. J Hazard Mater 161:723-729

Manta DS, Angelone M, Bellanca A, Neri R, Sprovieri M (2002) Heavy metals in urban soils: a case study from the city of Palermo (Sicily), Italy. Sci Total Environ 300:229-243

Mohiuddin KM, Zakir HM, Otomo K, Sharmin S, Shikazono N (2010) Geochemical distribution of trace metal pollutants in water and sediments of downstream of an urban river. Int $\mathbf{J}$ Environ Sci Tech 7(1):17-28

Monken FH (1997) Heavy metal distribution in sediments and ecological risk assessment: the role of diagenetic processes in reducing metal toxicity in bottom sediments. Environ Pollut 97(3):317-325

Moriilo J, Usero J, Gracia I (2004) Heavy metal distribution in marine sediments from the southwest coast of Spain. Chemosphere $55: 431-442$

Roussiez V, Ludwig W, Monaco A, Probst JL, Bouloubassi I, Buscail R, Saragoni G (2006) Sources and sinks of sediment-bound contaminants in the Gulf of Lions (NW Mediterranean Sea): a multi-tracer approach. Cont Shelf Res 26(16):1843-1857

Sekabira K, Oryem Origa H, Basamba TA, Mutumba G, Kakudidi E (2010) Assessment of heavy metal pollution in the urban stream sediments and its tributaries. Int $\mathrm{J}$ Environ Sci Technol 7(3):435-446

Singh KP, Mohan D, Singh VK, Malik A (2005) Studies on distribution and fractionation of heavy metals in Gomti river sediments - a tributary of the Ganges, India. J Hydrol (Amst) 312:14-27

Su LY, Liu JL, Christensen P (2011) Spatial distribution and ecological risk assessment of metals in sediments of Baiyangdian wetland ecosystem. Ecotoxicology 20:1107-1116

Teasdale PR, Apte SC, Ford PW (2003) Geochemical cycling and speciation of copper in waters and sediments of Macquarie Harbour, Western Tasmania. Estuar Coast Shelf Sci 57:475-487

Townsend JM, Rimmer CC, Driscoll CT, McFarland KP (2013) Mercury concentrations in tropical resident and migrant songbirds on Hispaniola. Ecotoxicology 22:50-59

Turekian KK, Wedepohl KH (1961) Distribution of the elements in some major units of the Earth's crust. Geol Soc Am Bull 72:175-192

Wang H, Wang CX, Wang ZJ (2002) Speciations of heavy metals in surface sediment of Taihu Lake. Environ Chem 21:430-435

Wang MY, Zhang L, Qin YW, Li FS, Jia J, Cao W, Zheng BH (2011) Speciation of heavy metals in sediments from Xiang River and analysis of their environmental factors. Acta Scientiae Circumstantiae 31(11):2447-2458

Wang SL, Lin CY, Cao XZ, Zhong X (2012) Arsenic content, fractionation, and ecological risk in the surface sediments of lake. Int J Environ Sci Technol 9:31-40

Yan CZ, Li QZ, Zhang X, Li GX (2010) Mobility and ecological risk assessment of heavy metals in surface sediments of Xiamen Bay and its adjacent areas, China. Environ Earth Sci 60:1469-1479

Yi YJ, Yang ZF, Zhang SH (2011) Ecological risk assessment of heavy metals in sediment and human health risk assessment of heavy metals in fishes in the middle and lower reaches of the Yangtze River basin. Biol Trace Elem Res 129:270-277

Yu RL, Hu GR (2008) Speciation and ecological risk of heavy metals in sediments from Quanzhou Bay. J Huaqiao Univ (Nat Sci) 29(3):419-423 (in Chinese)

Zhang M, Cui L, Sheng L, Wang Y (2009) Distribution and enrichment of heavy metals among sediments, water body and plants in Hengshuihu Wetland of Northern China. Ecol Eng 35(4):563-569 
Zhang GS, Liu DY, Wu HF, Chen LL, Han QX (2012) Heavy metal contamination in the marine organisms in Yantai coast, northern Yellow Sea of China. Ecotoxicology 21:1726-1733
Zheng SA, Zheng XQ, Chen C (2013) Transformation of metal speciation in purple soil as affected by waterlogging. Int $\mathbf{J}$ Environ Sci Tech 10:351-358 